\title{
Mielopatia compressiva por lipoma de células fusiformes infiltrativo em cão
}

\author{
Compressive myelopathy by infiltrative spindle cell lipoma in a dog \\ Rosmarini Passos dos Santos ${ }^{\mathrm{I}}$ Glaucia Denise Kommers ${ }^{\mathrm{II}}$ Ricardo Barbosa Lucena ${ }^{\mathrm{I}}$ \\ Diego Vilibaldo Beckmann ${ }^{\mathrm{I}}$ Graciane Aiello $^{\mathrm{I}}$ Cristiano Gomes $^{\mathrm{I}}$ Angel Ripplinger $^{\mathrm{IV}}$ \\ Alexandre Mazzanti ${ }^{\text {II }}$
}

\section{- NOTA -}

RESUMO

Relata-se um caso de lipoma de células fusiformes infiltrativo diagnosticado em cadela com sinais neurológicos de ataxia proprioceptiva, reação postural ausente no membro pélvico direito, paraparesia fracamente ambulatória e dor à palpação sobre as vértebras torácicas craniais. A mielografia demonstrou compressão extradural do lado direito sobre a quinta vértebra torácica. À necropsia foi observado neoplasma que invadia o canal vertebral na quarta e quinta vértebras torácicas com compressão acentuada da medula espinhal. Microscopicamente, foram observados adipócitos neoplásicos bem diferenciados, com áreas de células fusiformes, diagnosticado como lipoma de células fusiformes infiltrativo. A avaliação por imuno-histoquímica, com anticorpo anti-CD34, revelou positividade principalmente nas áreas fusiformes do lipoma.

Palavras-chave: cão, lipoma, imuno-histoquímica.

\section{ABSTRACT}

A female dog was referred presenting neurological signs of proprioceptive ataxy, proprioceptive deficit in the right pelvic limb, mild ambulatory paresis and spinal pain during the palpation in thoracic vertebrae. It was observed a right extradural compression of spinal cord over fourth and fifth thoracic vertebrae by spinal myelography. During necropsy evaluation, it was observed a neoplasm which infiltrated in the spinal canal in the fourth and fifth thoracic vertebrae with marked compression of the spinal cord. Microscopically there were well differentiated neoplasic adipocytes, with areas of spindle cells, diagnosed as infiltrative spindle cell lipoma. The immunohistochemical staining revealed positive CD34 cells mainly in the areas of spindle cells lipoma.

Key words: dog, lipoma, immunohistochemistry.
Os lipomas infiltrativos são histologicamente idênticos aos demais lipomas e tem origem nos adipócitos do tecido subcutâneo, porém são invasivos e podem causar sinais clínicos devido à compressão dos tecidos adjacentes (MORGAN et al., 2007). O lipoma de células fusiformes é uma variante, benigna e rara, descrita em humanos e cães (GROSS et al., 2009).

Os lipomas infiltrativos possuem maior prevalência em cães das raças Labrador Retriever e Doberman Pinchers e em cães sem raça definida (KIM et al., 2005). Acometem frequentemente cães de meia idade e as fêmeas tem uma maior predisposição em comparação aos machos (MCCHESNEY et al., 1980; KRAMEK et al., 1985; BERGMAN et al., 1994; STUBBS et al., 1996). O diagnóstico definitivo pode ser estabelecido após biópsia cirúrgica ou necropsia e o tratamento cirúrgico pode ser efetivo na maioria dos casos, resultando em maior sobrevida (MCENTEE \& THRALL 2001).

Os lipomas infiltrativos são observados em cães (GLEISER et al., 1979; MCCHESNEY et al., 1980; KRAMEK et al., 1985; BERGMAN et al., 1994; STUBBS et al., 1996; MCENTEE et al., 2000; MCENTEE \& THRALL, 2001), mas o relato desse neoplasma invadindo o canal vertebral e

\footnotetext{
'Programa de Pós-graduação em Medicina Veterinária, Centro de Ciências Rurais (CCR), Universidade Federal de Santa Maria (UFSM), Camobi, Santa Maria, RS, Brasil.

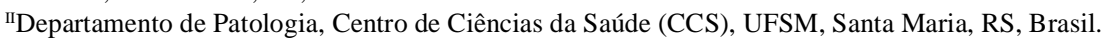

IIIDepartamento de Clínica de Pequenos Animais, CCR, UFSM, 97105-900, Santa Maria, RS, Brasil. E-mail: alexamazza@yahoo.com.br. Autor para correspondência.

${ }^{\text {IV }}$ Curso de Medicina Veterinária, CCR, UFSM, Santa Maria, RS, Brasil.
} 
provocando compressão medular é infrequente (KIM et al 2005; MORGAN et al., 2007). Além disso, não foi encontrada na literatura descrições de lipomas de células fusiformes em cães com comportamento infiltrativo. Diante disso, objetivo deste trabalho foi relatar os aspectos clínico-patológicos e a característica histológica do lipoma de células fusiformes infiltrativo com compressão extradural da medula espinhal torácica em uma cadela.

Foi atendida no Hospital Veterinário da Universidade Federal de Santa Maria, uma cadela sem raça definida, com 11 anos de idade, pesando $8,1 \mathrm{~kg}$, com histórico de aumento de volume na região torácica dorsal direita (Figura1A) havia quatro meses e sinais de desconforto na região. No exame neurológico, a cadela estava alerta, apresentava ataxia proprioceptiva nos membros pélvicos, paraparesia fracamente ambulatória, reação postural (posicionamento proprioceptivo) normal nos membros torácicos e no pélvico esquerdo e ausente no direito (assimetria de sinais), reflexos segmentares espinhais torácicos (flexor), pélvicos (patelar, flexor e perineal) e tônus muscular normal e dor à palpação na coluna vertebral torácica. Os sinais neurológicos observados caracterizaram lesão entre T3 e L3 da medula espinhal.

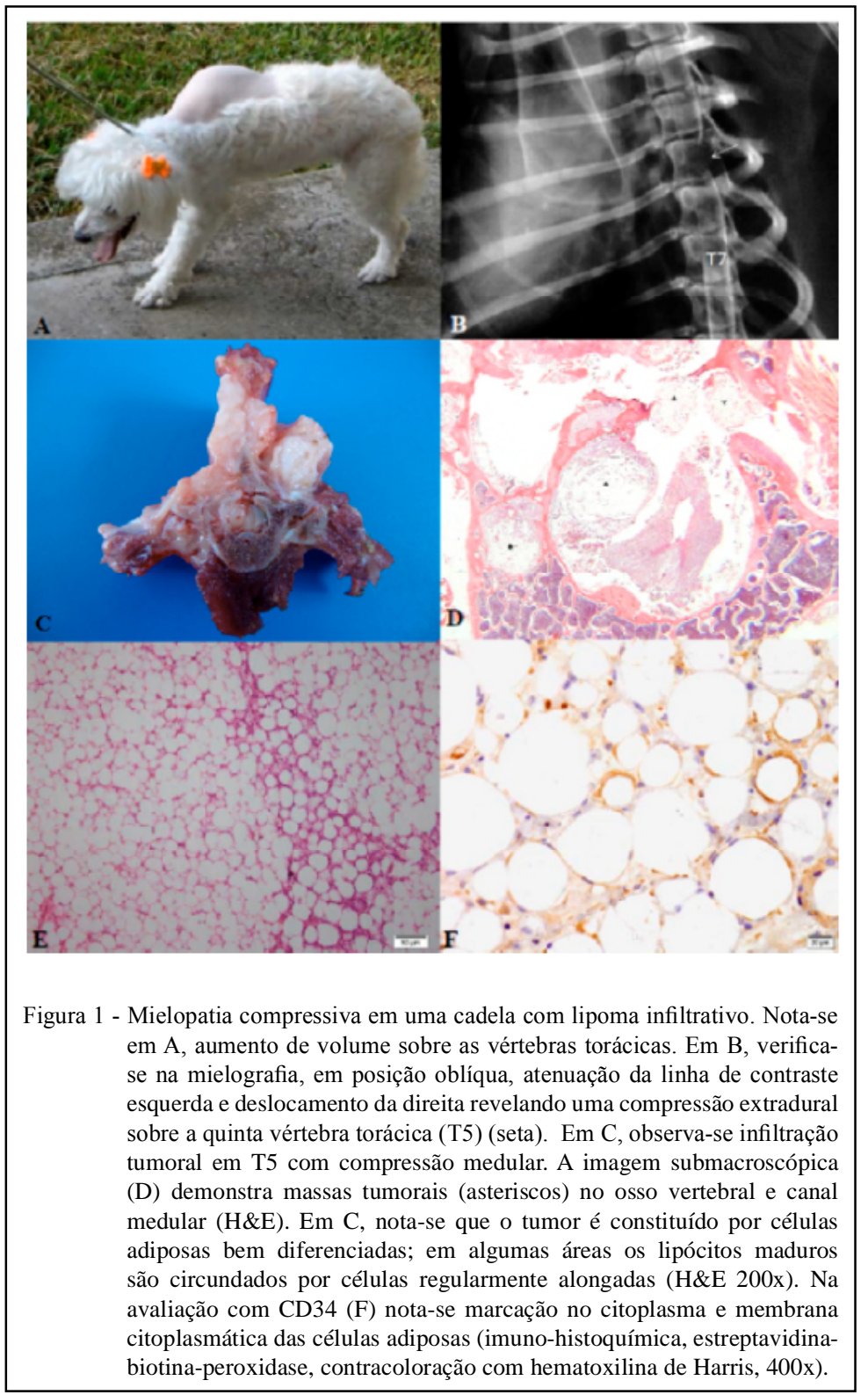

Ciência Rural, v.43, n.5, mai, 2013. 
Os exames complementares realizados incluíram: hemograma (Ht $36,9 \% \quad$ [37-55]; hemoglobina $12,5 \mathrm{~g} \mathrm{dL}^{-1}$ [12-18]; VCM 73,8fL [6077], CHCM 33,8\% [32-36]; leucócitos totais 10.100 $\mu \mathrm{L}-1$ [6000-17000] e bioquímica sérica (Creatinina: 1,1mg dL $\mathrm{m}^{-1}$ [0,5-1,5]; ALT: 376UI L-1 [21-102]; FA: $\left.110,4 \mathrm{UI} \mathrm{L}^{-1}[20-156]\right)$; punção aspirativa por agulha fina do aumento de volume (presença de adipócitos e células mesenquimais com discreta anisocitose, fusiformes e com bordos indistintos); ultrassom de abdome e radiografia simples do tórax sem alterações; radiografia da coluna vertebral (lise óssea do processo espinhoso da terceira vértebra torácica), análise do liquor ( 2 células $\mu \mathrm{L}^{-1}$, proteína $32 \mathrm{mg} \mathrm{dl}^{-1}$ ) e mielografia (desvio da linha dorsal de contraste na região da quinta vértebra torácica).

Inicialmente foi instituída terapia de suporte com prednisona em doses decrescentes por quinze dias. O quadro clínico continuou progredindo e evoluiu para paraparesia ambulatória severa, sendo realizada a eutanásia por opção do proprietário. Foi observada durante a necropsia que a massa invadia o canal vertebral da quarta e quinta vértebras torácicas causando acentuada compressão da medula espinhal. O diagnóstico histopatológico foi de lipoma de células fusiformes infiltrativo. A avaliação imunohistoquímica (IHQ), feita com anticorpo anti-CD34a (clone QBEnd 10, diluição: 1:50), confirmou o diagnóstico.

O aumento de volume observado sobre a coluna vertebral torácica na paciente desse relato, associado aos sinais neurológicos, permitiu suspeitar de uma provável invasão da massa tumoral para o canal vertebral, o que foi confirmado durante a necropsia (Figura C). Com isso, pode-se concluir que a evolução progressiva e os sinais neurológicos assimétricos observados foram em decorrência do neoplasma que envolvia a medula espinhal. Os mesmos sinais neurológicos foram encontrados por LEWIS et al. (1991) em um cão com mielopatia compressiva em decorrência de lipossarcoma que atingia a primeira e segunda vértebras lombares.

A hiperestesia na coluna vertebral, caracterizada por vocalização e apatia, foi o primeiro sinal clínico notado pela proprietária. Em compressões extradurais da medula espinhal, essa manifestação clínica inicial é um achado comum (DEWEY, 2003) e pode ser ocasionada pelo envolvimento do periósteo e/ou meninges (DE BRUINE \& BONGARTZ, 1983), já que essas estruturas apresentam uma grande quantidade de nociceptores e geralmente estão envolvidas na hiperestesia (PLATT, 2004). Sinas semelhantes foram observados por MORGAN et al. (2007) e KIM et al. (2005) em cães com lipoma infiltrativo que comprimia a medula espinhal.

Os exames de imagens utilizados para auxílio ao diagnóstico foram a radiografia simples, que demonstrou lise óssea do processo espinhoso da terceira vértebra torácica, e a contrastada (mielografia) que revelou deslocamento da linha de contraste direita sugestivo de compressão extradural (Figura 1B). Não foram encontradas evidências de metástases nas imagens radiográficas do tórax e nas de ultrassom abdominal. Nas análises hematológica e bioquímica foi possível perceber apenas aumento do nível sérico de ALT provavelmente resultante da corticoterapia. Nos cães, os locais mais comuns de ocorrência do lipoma infiltrativo são as extremidades dos membros (MCCHESNEY et al., 1980; BERGMAN et al., 1994), as paredes torácica e abdominal, a cabeça e a região perineal (GLEISER et al., 1979; MCCHESNEY et al., 1980; BERGMAN et al., 1994). Porém, com envolvimento da medula espinhal, como na cadela deste relato, são poucos os casos (MORGAN et al., 2007; KIM et al., 2005). Embora a presença de compressão da medula espinhal principalmente sobre o corpo vertebral ao invés do espaço intervertebral não seja considerado um sinal patognomônico de compressão extradural provocado por neoplasma (BAGLEY, 2010), estes achados auxiliaram na exclusão da doença do disco intervertebral.

O tratamento cirúrgico geralmente é recomendado em pacientes com neoplasmas envolvendo a medula espinhal por ser mais efetivo e resultar em maior sobrevida (KIM et al., 2005; BAGLEY,2010), o que não foi aceito pela proprietária. Diante disso, optou-se pelo tratamento com corticoide durante 14 dias, sem evidências de melhora clínica. Este resultado coincidiu com os achados de DEWEY (2003), que observou um prognóstico desfavorável para cães e gatos com neoplasma na medula espinhal tratados somente com terapia de suporte.

O estudo histopatológico realizado na massa tumoral revelou tecido adiposo neoplásico composto por adipócitos maduros bem diferenciados com áreas de células fusiformes, altamente infiltrativo, que se estendia do tecido subcutâneo da região torácica dorsal direita aos músculos torácicos na região da terceira até a nona vértebra torácica. $\mathrm{O}$ lipoma invadia a terceira, quarta e quinta vértebras torácicas (Figura D), com infiltração para dentro do canal vertebral, causando acentuada compressão da medula espinhal (Figura E) sobre a quarta e quinta vértebras torácicas. A IHQ revelou positividade para CD34 predominantemente nas áreas de células fusiformes do tumor (Figura F). Este resultado

Ciência Rural, v.43, n.5, mai, 2013. 
confirma o diagnóstico de lipoma de células fusiformes (GROSS et al., 2009). Mesmo com as alterações neurológicas e histopatológicas e do tempo de evolução encontradas na paciente, o prognóstico quanto à recuperação funcional seria reservado após descompressão cirúrgica.

O caso traz como relevância clínica os sinais clínicos progressivos, os achados neurológicos de lesão assimétrica, as imagens encontradas na mielografia, e a descrição histológica e imunohistoquímica de uma rara variante de lipoma infiltrativo com padrão de células fusiformes com invasão das vértebras torácicas, comprimindo a medula espinhal.

\section{FONTES DE AQUISIÇÃO}

a - Anti-CD34, Dako, Glostrup, Dinamarca.

\section{REFERÊNCIAS}

BAGLEY, R.S. Spinal neoplasms in small animals. Veterinary Clinics of North America: Small Animal Practice, v.40, n.5, p.915-928, 2010. Disponível em: <http://www.ncbi. nlm.nih.gov/pubmed/20732598>. Acesso em: 10 jun. 2011. doi: 10,1016/j.cvsm.2010.05.010.

BERGMAN, P.J. et al. Infiltrative lipoma in dogs: 16 cases (1981-1992). Journal of the American Veterinary Medical Association, v.205, n.2, p.322-324, 1994.

DE BRUINE, J.F.; BONGARTZ, E.B. Spinal extradural lipomas. Report of two cases. Clinical Neurology Neurosurgery, v.85, n.3, p.181-190, 1983.

DEWEY, C.W. Myelopathies: disorders of the spinal cord. In: A practical guide to canine and feline neurology. 3.ed.

Iowa: Blackwell, 2003. Cap.9, p.277-336.

GLEISER, C.A. et al. Infiltrating lipomas in the dog. Veterinary Pathology, v.16, p.623-624, 1979.
GROSS, T.L. et al. Tumores lipocíticos. In: ___ Doenças da pele do cão e do gato. Diagnóstico clínico e histopatológico. 2.ed. São Paulo: Roca, 2009. Cap.30, p.750-761.

KIM, H.J. et al. Infiltrative lipoma in cervical bones in a dog. Journal of Veterinary Medical Science, v.67, p.10431046, 2005. Disponível em: <http://www.ncbi.nlm.nih.gov/ pubmed/16276061>. Acesso em: 10 jun. 2011. doi: 10.1292/ jvms.67.1043.

KRAMEK, B.A. et al. Infiltrative lipoma in three dogs. Journal of the American Veterinary Medical Association, v.186, n.1, p.81-82, 1985 .

LEWIS, D.D. et al. Extradural spinal liposarcoma in a dog. Journal American Veterinary Medical Association, v.199, n.11, p.1606-1607, 1991.

MCCHESNEY, A.E. et al. Infiltrative lipoma in dogs. Veterinary Pathology, v.17, n.3, p.316-322, 1980.

MCENTEE, M.C. et al. Results of irradiation of infiltrative lipoma in 13 dogs. Veterinary Radiology and Ultrasound, v.41, n.6, p.554-556, 2000. Disponível em: <http://onlinelibrary.wiley.com/ doi/10.1111/j.1740-8261.2000.tb01889.x/abstract>. Acesso em: 10 jun. 2011. doi: 10.1111/j.1740-8261.2000.tb01889.x.

MCENTEE M.C.; THRALL D.E. Computed tomographic imaging of infiltrative lipoma in 22 dogs. Veterinary Radiology and Ultrasound, v.42, n.3, p.221-225, 2001. Disponível em: <http://onlinelibrary.wiley.com/doi/10.1111/j.1740-8261.2001. tb00928.x/abstract>. Acesso em: 10 jun. 2011. doi: 10.1111/ j.1740-8261.2001.tb00928.x.

MORGAN, L.W. et al. Imaging diagnosis--infiltrative lipoma causing spinal cord compression in a dog. Veterinary Radiology and Ultrasound, v.48, n.1, p.35-7, 2007. Disponível em: <http:// onlinelibrary.wiley.com/doi/10.1111/j.1740-8261.2007.00201.x/ abstract; jsessionid=5381323596167B2DDEB8A2CD60302151. $\mathrm{d} 04 \mathrm{t} 01$ ?denied AccessCustomisedMessage $=\&$ userIs Authenti cated=false $>$. Acesso em: 10 jun. 2011. doi: 10.1111/j.17408261.2007.00201.x.

PLATT, S.R. Neck and back pain. In: PLATT, S.R.; OLBY, N.J. Canine and feline neurology. 3.ed. Gloucester: BSAVA, 2004. Cap.13, p.202-213.

STUBBS, W.P. et al. What is your diagnosis? Infiltrative lipoma with chronic salivary duct obstruction. Journal of the American Veterinary Medical Association, v.209, n.1, p.55-56, 1996. 